Original Research Article

\title{
Variable potentiation of analgesic anti- inflammatory activity of diclofenac by two medicinal plants rubia cordifolia and cassia fistula in wistar albino rats
}

\author{
Rajashekar Y. R. ${ }^{1 *}$, Shobha S. N. ${ }^{2}$
}

\begin{abstract}
${ }^{1}$ Department of Pharmacology, ${ }^{2}$ Department of Pathology, Adichunchanagiri Institute of Medical Sciences, BG Nagar, Mandya, Karnataka, India
\end{abstract}

Received: 21 February 2017 Accepted: 25 February 2017

*Correspondence to:

Dr. Rajashekar Y. R.,

Email:

rajashekar.yr@gmail.com

Copyright: (๑) the author(s), publisher and licensee Medip Academy. This is an openaccess article distributed under the terms of the Creative Commons Attribution NonCommercial License, which permits unrestricted noncommercial use, distribution, and reproduction in any medium, provided the original work is properly cited.

\begin{abstract}
Background: NSAIDS are commonly prescribed drugs in clinical practice. However, their usage is limited by their toxicity profile and research continues for an alternative therapy with higher efficacy and safety. Various plant preparations found to be safe and effective are emerging, but their interactions with synthetic drugs are not much known.

Methods: Wistar rats were divided in to four groups of six animals each Rubia cordifolia (RC) root preparation and casissia fistula (CF) leaf preparation were studied with sub anti-inflammatory dose of diclofenac in various analgesic, acute and subacute inflammatory models and test results variables were expressed in mean reaction time, paw edema volume and granuloma weight respectively.

Results: Various test results were tabulated, statistically analysed and significance was calculated at $\mathrm{P}$ value $<0.5$. Eddy's hot plate model did not show any significant change, but carrageenan induced paw edema model and cotton pellet induced granuloma model showed comparable decrease in paw edema volume and granuloma dry weight.

Conclusions: Diclofenac, a standard analgesic and anti -inflammatory was not potentiated in pain model but it was potentiated in carrageenan and cotton pellet granuloma models in a variable manner. CF potentiates acute anti-inflammatory action, whereas RC potentiates subacute anti-inflammatory actions of diclofenac.
\end{abstract}

Keywords: Analgesic - antiinflammatory, Diclofenac, Cassia fistula (CF), Potentiation, Rubia cardifolia (RC)

\section{INTRODUCTION}

Pain and inflammation are the disabling symptoms of the most of the clinical disorders and controlling them are very much challenging task for the physician. ${ }^{1}$ Non steroidal anti- inflammatory drugs (NSAIDs) are the most commonly prescribed drugs in the clinical practice and are effective in providing symptomatic relief in patients of painful inflammatory or arthritic conditions. Unfortunately, their variable toxicities limit their continued use in such patients. Each year as many as 2000 deaths in united kingdom, 7600 deaths and 76,000 hospitalization in united states and 365 deaths and 3900 hospitalization in Canada. ${ }^{2,3}$ This may be attributable to
NSAIDs over usage and their toxicity profile includes mainly gastrointestinal system, though renal, liver, cardiovascular and skin associated problems are not infrequent. Hence there is always a scope for more effective, yet safer agents in the therapy of pain and inflammation.

Historically, medicinal plants have been considered to be prospective source of novel anti-inflammatory agents following the discovery of Aspirin, from willo bark. The tribal and rural population of India largely depends on the medicinal plants for their health care for thousands of years and these plant derived medicines have none of the side effects that are so common with the synthetic drugs. 
Literature survey reveals some of the medicinal plants like Acacia catechu (cutch tree) and Eucalyptus citriodora (lemon gum) and many more have been found to have variable analgesic and anti-inflammatory properties. ${ }^{4}$ And these can definitely open up new vistas in painful inflammatory conditions. Medicinal herbs are moving from fringe to mainstream use, as they have been found to be effective and safe in various scientific studies. In India more than 6000 plants are in use in traditional folk and herbal medicine, as they are found to be free from side effects. ${ }^{5}$

A known ayurvedic herb Rubia cordifolia Linn, commonly known as Indian Madder, found to have antimicrobial, anticancer, analgesic, antipyretic, antiinflammatory, antiarthritic, antihelminthic, antioxidant, immune modulating, blood purifying and diuretic properities. $^{4-6}$

Another ayurvedic plant Cassia Fistula Linn, commonly known as Golden shower, has been found to have antifungal, antimicrobial, antioxidant, analgesic, antiinflammatory, antitumor, hepato protective and hypoglycaemic activities. ${ }^{7}$

These two plant preparations have been extensively studied and found to have very good analgesic and antiinflammatory actions. There is paucity of information regarding the interaction of these two plant preparations with Diclofenac and other NSAIDs.

Thus, the aim and objectives of this study is to explore the interactions of CF and RC preparations with sub antiinflammatory dose of Diclofenac in various analgesic and anti-inflammatory models.

\section{METHODS}

\section{Experimental animals}

Healthy Wistar albino rats with normal behaviour and activity of age group 2-3 months, weighing around 150250 grams of either sex were randomly selected and divided in to 4 groups of 6 animals each. Diseased, pregnant and previously experimented animals were excluded from the study. Animals were obtained from college central animal house, maintained in standard laboratory conditions with 12 hrs alternate day and night cycle and fed with standard diet and filtered water ad libitum.

Animals were acclimatized to the experimental conditions for about one week before the experiment and the experiment was conducted in the central research lab between 9 am to $4 \mathrm{pm}$. The food and water were removed during experiment hours and were administered with appropriate dose of the test and standard drugs.

- Group 1- Control Normal saline $1 \mathrm{ml}$ PO

- Group 2- Standard -Diclofenac $13.5 \mathrm{mg} / \mathrm{kg}$ bw PO
- $\quad$ Group 3- Test drug $1 \mathrm{RC}$ root preparation $300 \mathrm{mg} / \mathrm{kg}$ bw + sub anti- inflammatory dose of Diclofenac $5 \mathrm{mg} / \mathrm{kg}$ bw PO

- $\quad$ Group 4- Test drug 2 CF leaf preparation $500 \mathrm{mg} / \mathrm{kg}$ bw + sub anti- inflammatory dose of Diclofinac $5 \mathrm{mg} / \mathrm{kg}$ bw PO

\section{Eddy's hot plate model}

The Hot plate was maintained at $55^{\circ} \mathrm{C}$ and animals were placed on it. The time of discomfort reaction (licking paw or jumping) of the animal was recorded as response reaction time in seconds. Readings were taken prior to and 30 and 60 minutes after the saline/drug administration was made in both control and treated groups. Longer reaction time of treated group indicated analgesic activity.

\section{Carrageenan induced paw edema model}

$0.1 \mathrm{ml}$ of $1 \%$ carrageenan was injected subcutaneously in to the plantar surface of the rat hind paw of both treatment and control groups under aseptic conditions. Paw edema was measured at 0, 30, 60, 180 and 300 minutes with the help of manual mercury plethysmograph. The reduction of paw edema in treated groups in comparision with the control groups indicated anti-inflammatory activities.

\section{Cotton pellet induced granuloma model}

Under thiopentone sodium anaesthetia with aseptic measures, weighed cotton pellets were introduced subcutaneously in each axilla of rats and incised wounds were closed in both treatment and control groups. Treatment was continued for 7 days and on 8 day inserted cotton pellets with granulation tissue was removed under anaesthetia. Obtained granuloma was dried in hot air oven at $60^{\circ} \mathrm{C}$ and weighed. Weight reduction of dried pellets of treatment group in comparison with control group indicated sub anti-inflammatory activity of the drugs.

\section{RESULTS}

Result variables expressed as reaction time in seconds, paw edema volume in $\mathrm{ml}$ and granuloma weight in $\mathrm{mg}$ were tabulated and statistical significance was calculated at $\mathrm{P}$ value $<0.5$ using unpaired t- test.

\section{Eddy's hot plate method}

The mean reaction time of Diclofenac treated group was highly statistically significant when compared to that of control at 60 minutes. Coadministration of relatively high dose of RC preparation $(300 \mathrm{mg} / \mathrm{kgbw})$ and $\mathrm{CF}$ preparation $(500 \mathrm{mg} / \mathrm{kgbw})$, with sub anti-inflammatory dose of Diclofenac did not prolong the mean reaction time significantly and it was similar to that of control. 
Table 1: Reaction time in seconds at 30 and 60 minutes.

\begin{tabular}{|llllll|} 
& Number & $\begin{array}{l}\text { Mean } \pm \text { SD } \\
\mathbf{3 0} \text { min }\end{array}$ & $\begin{array}{l}\text { \% Inhibition } \\
\mathbf{3 0} \text { min }\end{array}$ & $\begin{array}{l}\text { Mean } \pm \text { SD } \\
\mathbf{6 0} \text { min }\end{array}$ & $\begin{array}{l}\text { \% Inhibition } \\
\mathbf{6 0} \text { min }\end{array}$ \\
\hline Control & 6 & $6.31 \pm 1.1$ & & $6.1 \pm 0.9$ & \\
\hline Diclofenac (Standard)13.5 mg/kgbw & 6 & $10.1 \pm \_2.5$ & 90 & $14.1 \pm 2.8$ & $146^{* *}$ \\
\hline RC 300mg/kgbw+Diclofenac 5mg/kgbw & 6 & $6.35 \pm 1.3$ & 9 & $6.5 \pm 1.1$ & 18 \\
\hline CF 500mg/kgbw+Diclofenac 5mg/kgbw & 6 & $6.7 \pm 1.4$ & 10 & $7.1 \pm 1.8$ & 20 \\
\hline
\end{tabular}

Table 2: Carrageenan induced paw edema volume in $\mathrm{ml}$.

\begin{tabular}{|lll|l|}
\hline & No. & $\begin{array}{l}\text { Mean } \pm \text { SD } \\
\mathbf{3 0 ~ m i n ~}\end{array}$ & $\begin{array}{l}\% \\
\text { Inhibition } \\
\mathbf{6 0} \text { min }\end{array}$ \\
\hline Control & 6 & $2.1 \pm 0.6$ & \\
\hline $\begin{array}{l}\text { Diclofenac (Standard) } \\
13.5 \mathrm{mg} / \mathrm{kgbw}\end{array}$ & 6 & $1.1 \pm 0.4$ & $50 * *$ \\
\hline $\begin{array}{l}\mathrm{RC} \\
300 \mathrm{mg} / \mathrm{kgbw}+\text { Diclofe }\end{array}$ & 6 & $1.8 \pm 0.7$ & 13 \\
nac 5mg/kgbw & & & \\
\hline $\begin{array}{l}\mathrm{CF} \\
500 \mathrm{mg} / \mathrm{kgbw}+\text { Diclofe } \\
\text { nac 5mg/kgbw }\end{array}$ & 6 & $1.6 \pm 0.5$ & $22 *$ \\
\hline
\end{tabular}

\section{Carrageenan induced paw edema model-}

Diclofenac treated group reduced the rat paw edema at 30, 60.180 and 300 minutes significantly (Table shows only 60 minutes results), when compared to control group. Co administration of RC (300mg/kgbw) with sub anti-inflammatory dose of Diclofenac $(5 \mathrm{mg} / \mathrm{kgbw})$ did not inhibit paw edema volume and the \% inhibition was 13, while that of Diclofenac group was 50, at 60 minutes. However CF preparation showed \% inhibition of 22 with sub anti-inflammatory dose of Diclofenac having some statistical significance.

\section{Table 3: Cotton pellet induced granuloma dry} weight in $\mathrm{mg}$.

\begin{tabular}{|llll|}
\hline & No. & Mean \pm SD & $\begin{array}{l}\% \\
\text { Inhibition }\end{array}$ \\
\hline Control & 6 & $25 \pm 1.6$ & \\
\hline $\begin{array}{l}\text { Diclofenac } \\
\text { (Standard) } 13.5\end{array}$ & 6 & $14 \pm 1.1$ & $60 * *$ \\
mg/kgbw & & $17.6 \pm 1.6$ & $31^{*}$ \\
\hline $\begin{array}{l}\text { RC } \\
300 \mathrm{mg} / \mathrm{kgbw}+\mathrm{Dic} \\
\text { lofenac 5mg/kgbw }\end{array}$ & 6 & & \\
\hline $\begin{array}{l}\mathrm{CF} \\
500 \mathrm{mg} / \mathrm{kgbw}+\mathrm{Dic} \\
\text { lofenac 5mg/kgbw }\end{array}$ & 6 & $21 \pm 1.8$ & 22 \\
\hline
\end{tabular}

Cotton pellet induced granuloma model- Diclofenac treated group was found to have very high significant $\%$ inhibition of 60, as shown in Eddy's hot plate model \& in carrageenan paw edema models. In this model, RC preparation was found to have higher significant $\%$ inhibition of 31 than CF preparation with $22 \%$, when co administered with sub anti inflammatory dose of Diclofenac.

\section{DISCUSSION}

Rubia cardiofolia (RC) root and Cassia fistula (CF) leaf preparations have been extensively studied already and found to be having wide pharmacological actions. ${ }^{8,9}$ The fact that they are the one of the main ingredients of many marketed herbal medicines, upholds their efficacy and safety profiles. Our study was aimed at evaluating interaction of these two plant preparations with a widely prescribed NSAID, Diclofenac. It itself, a very much potent analgesic and anti-inflammatory agent has very high statistical significance. It was used in two strengths, one was $13.5 \mathrm{mg} / \mathrm{kgbw}$ (therapeutic equivalent human dose) and other one was $5 \mathrm{mg} / \mathrm{kgbw}$ (subantiinflammatory dose), calculated by giving a series of Diclofenac doses in Wistar albnino rats and at this dose no anti-inflammatory response was seen.

Our previous study showed these two plant products have good analgesic and anti-inflammatory actions, but not equivalent to that of Diclofenac and this result is in consistence with other studies. ${ }^{10}$

In Eddy's hot plate method, the reaction time of both the test groups at 60 and 30 minutes were not much significant from that of saline control suggesting that both RC and CF preparations did not have any interaction with sub anti-inflammatory dose of Diclofenac. Thus analgesic action of Diclofenac could not be enhanced by adding any of two test preparations. However their role in reducing gastric toxicity of Diclofenac is yet to be studied.

In carrageenan induced paw edema model, CF leaf preparation administered with sub anti-inflammatory dose of Diclofenac significantly reduced the paw edema volume by $22 \%$ suggesting a potent anti-inflammatory action. And thus potentiation anti-inflammatory action of Diclofenac occurred with it. Whereas RC root preparation did not show any significant interaction with Diclofenac. 
In cotton pellet induced granuloma model RC root preparation with sub anti-inflammatory dose of Diclofenac found to decrease granuloma dry weight by $22 \%$. This inhibition suggests its potent subacute antiinflammatory action and thus potentiation of subacute anti-inflammatory dose of Diclofenac could be established. On the other hand $\mathrm{CF}$ leaf preparation potentiated anti-inflammatory action of Diclofenac in Carrageenan induced paw edema model, failed to do so here in this model. This is in consistence with other studies where NSAIDs actions are potentiated variably by other drugs like paracetamaol. ${ }^{9,10}$ Very difficult to explain this variable mechanism, possibly the dose, excipients used in aquous preparations, inflammatory mediators involved and mechanism of action of active ingredients determine this variable interaction. A lot more studies should be conducted to understand and go further

To summarize, RC root and CF leaf preparations did not potentiate the analgesic action of Diclofenac. RC root preparation potentiated the acute anti-inflammatory action, whereas CF leaf preparation potentiated the sub anti-inflammatory action of Diclofenac.

\section{CONCLUSION}

Alleviating pain and inflammation is a matter of concern. Presently used NSAIDs share many toxicities thus their usage is limited. Based on our present study favouring potentiaton, fixed dose combinations of Diclofenac with $\mathrm{RC}$ root and $\mathrm{CF}$ leaf preparations could be tried in order to decrease the potential toxicity of Diclofenac without compromising its efficacy in various painful clinical disorders. However studies are also required to explore such potential benefits on gastric and other toxicities of NSAIDs.

Funding: No funding sources

Conflict of interest: None declared

Ethical approval: The study was approved by the Institutional Ethics Committee

\section{REFERENCES}

1. Rang HP, Dale MN, Ritter JM, Henderson G. Analgesic Drugs. In: Rang and Dale's Pharmacology. $7^{\text {th }}$ edition. Edinburgh: Elsevier Churchill Livingstone; 2012:503.

2. Tramer MR, Moore RA, Reynolds DJ, MCQuay HJ. Quantative estimation of rare adverse events which follow a biological progression: a new model to chronic NSAID use. Pain. 2000;85(1-2):169-82.

3. Tamblyn R, Brkson L, Dauphinee WD. Unnecessary prescribing of NSAIDs and the management of NSAID- related gastropathy in medical practice. Annals of Internal Medicine. 1997;127(6):429-38.

4. Sengupta R, Sheorey SD, Hinge MA. Analgesic and anti-inflammatory Plants: An Updated Review. International Journal of Pharmaceutical sciences Review and Research. 2012;12(2):114-19.

5. Kasture SB, Kasture VS, Chopde CT. AntiOinflammatory a ctivity of Rubia Cordofolia roots. Jouranal of Natural Remedies. 2001;(1/2):11115.

6. Joharapurkar AA, Deode NM, Zambad SP, Umathe SN. Immunomodulatory activity of Alchoholic extract of Rubia Cordiofolia Linn. Indian Drugs. 2003;40(3):179-81.

7. Neelam C, Ranjan B, Komal S, Noothan C. Review on Cassis Fistula. International Journal of Research in Ayurveda and pharmacy. 2011;2(2):426-30.

8. Danish M, Singh P, Mishra G, Srivastava S, Jha KK, Khosa RL. Cassia fistula Linn. (Amulthus-)-An important Medicinal plant: A review of its Traditional uses, phytochemistry and pharmacological properties. Journal of Natural Product and plant Resources. 2011;1(1):101-18.

9. Wasu SJ, Muley BP. Hepatoprotective effect of Cassia Fistula Linn. Ethnobotanical Leaflets. 2009;13:910-16.

10. Wong S, Garadocki JF. Anti-inflammatory and antiarthritic evaluation of acetaminophen and its potentiation of tolmetin. J Pharmacol. Exp Ther. 1983;226:626-32.

Cite this article as: Rajashekar YR, Shobha SN. Variable potentiation of analgesic anti- inflammatory activity of diclofenac by two medicinal plants rubia cordifolia and cassia fistula in wistar albino rats. Int J Basic Clin Pharmacol 2017;6:746-9. 